\title{
EVALUATION OF THE APPLICATION OF A THERMAL INSULATION SYSTEM: IN-SITU COMPARISON OF SEASONAL AND DAILY CLIMATIC FLUCTUATIONS
}

\author{
JAn FořT ${ }^{a, *}$, PAVEl Beran ${ }^{b}$, Petr Konvalinka $^{a}$, ZByšEK PAVlík ${ }^{a}$, \\ ROBERT ČERNÝa \\ ${ }^{a}$ Czech Technical University in Prague, Faculty of Civil Engineering, Thákurova 7, 16629 Prague, Czech \\ Republic \\ ${ }^{b}$ Academy of Sciences of the Czech Republic, Institute of Theoretical and Applied Mechanics, Centre of \\ Excellence Telč / ARCCHIP, Batelovská 485-486, 58856 Teľc, Czech Republic \\ * corresponding author: jan.fort.1@fsv.cvut.cz
}

Abstract. The current outdated state of many institutional and administrative buildings in the EU region poses a significant burden from the energy sustainability point of view. According to the contemporary EU requirements on the energy efficiency of buildings maintenance, an evaluation of performed improvements is essential for the assessment of expended investments. This paper describes the effect of building envelope reconstruction works consisting in the installation of a thermal insulation system. Here, a long-term continuous monitoring is used for the extensive assessment of the seasonal and daily temperature and relative humidity fluctuations. The obtained results include temperature and relative humidity profiles in the wall cross-section as a response to the changing exterior climatic conditions. The analysis of measured data reveals substantial improvements in thermal stability of the analyzed wall during temperature peaks. While the indoor temperatures exceeding $28^{\circ} \mathrm{C}$ are recorded during summer before application of the thermal insulation layer, the thermal stability of the indoor environment is distinctly upgraded after performed improvements. Based on the complex long-term monitoring, a relevant experience is gained for the future work on energy sustainability and fulfilment of the EU directives.

KEYWORDS: in-situ monitoring; temperature; relative humidity; thermal insulation; energy sustainability; seasonal fluctuations.

\section{INTRODUCTION}

Building maintenance represents a substantial part in the total worldwide energy consumption. According to numerous studies, buildings pose a large and unexploited source for reduction of carbon dioxide emissions as well as potential energy savings. To be specific, buildings present the third most demanding sector after industry and transportation from the environmental point of view. Particularly, the heating and cooling requirements are responsible for almost $40 \%$ of the total energy consumed by the building sector [1]. Within the sustainable development, the new European directives are aimed at the better energy performance of buildings in all involved countries. According to the 2010/31/EU Directive, the public administration and institution buildings are considered as leading sector for making progress in the energy efficiency of buildings 2. Therefore, all member states are required to minimize energy demands related to the building maintenance. Moreover, for the new public administration and institution buildings, it will be obligatory to fulfil directive standards of a nearly zero energy building [3]. These commitments should be precisely defined at the national level, due to the exact definition of the nearly zero energy building. According to the provided 2012/27/EU Directive, proper strategies of investments for building renovations to increase modernization rate of current buildings are defined [4].

Notwithstanding, many institutional and public administration buildings in the Czech Republic are substantially outdated, especially from the thermal performance point of view. The buildings designed in previous decades, in many cases, do not provide stable ambient conditions, particularly during seasonal temperature fluctuations. They also do not meet the requirements on thermal comfort for inhabitants. Moreover, regarding the efforts to decrease the energy consumption, these outdated buildings with poor thermal performance require an installation of additional heating/cooling devices [5]. This common temporary solution is beneficial for managing the thermal comfort, but it unfortunately leads to an energy demanding and noisy service. Utilization of portable $\mathrm{A} / \mathrm{C}$ devices does not provide an adequate solution from the long-term perspective.

A proper understanding of the relationship between the exterior climatic conditions and the quality of the indoor environment is based on the monitoring of temperature, relative humidity, illumination, air quality, etc. 6]. The influence of the utilization of various monitoring techniques on energy reduction 


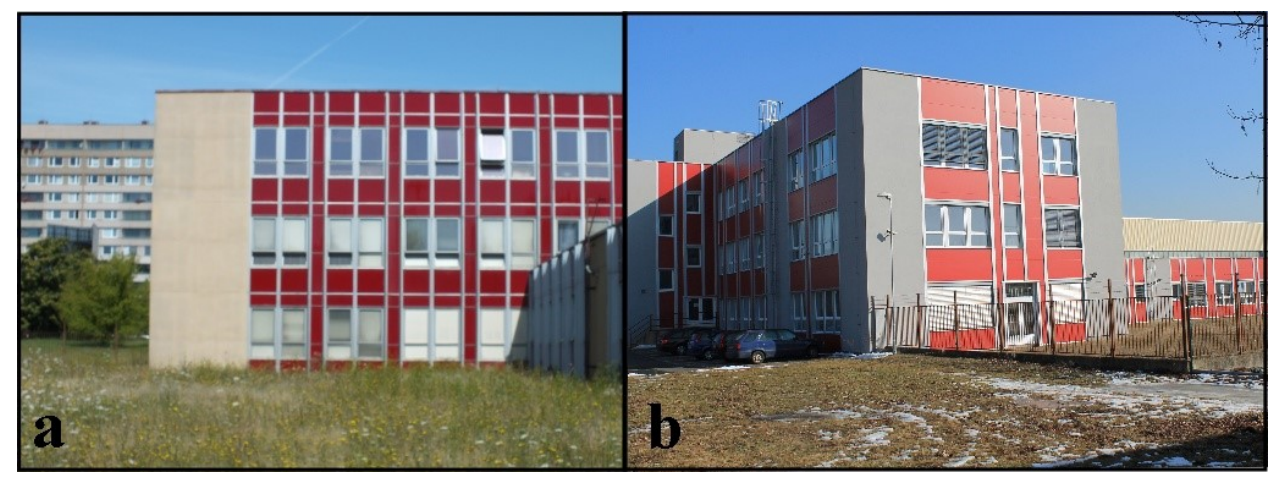

FIGURE 1. Photo of the studied building: before the application of thermal insulation (left); after reconstruction works (right).

solution was studied by Batista et al. [7]. Here, a decision based mainly on a building simulation is not recommended. The explanation of this conclusion lies in the differences between building plans and the real state of building including faults occurred during the construction process, which can significantly affect the obtained data.

The research methods can be categorized as qualitative and quantitative [8]. A spot or long-term monitoring methods can be distinguished in order to evaluate the indoor thermal comfort as well as the environment quality from the perspective of the quantitative methods [9]. From the environmental viewpoint, the total energy consumption related to the certain time interval is probably the mostly used evaluation method [10]. The life cycle assessment, primary consumption or carbon emissions equivalent are extensively used especially in relation to the life cycle of the building or particular materials [11]. The low thermal resistance of external walls of an outdated building is mostly fixed by the application of an exterior insulation system, which ensures substantial improvements of the thermal comfort as well as the energy sustainability. However, besides the accomplishment of the EU directives aimed at the nearly zero energy buildings, appropriate ambient climatic conditions and requirements must be ensured for the convenience of building residents [12].

Although modern energy efficiency measures are more less concentrated to the energy consumption, Mikulčioniene et al. 13 presented a multicriterial method to promote building retrofitting. Indoor thermal comfort can be perceived as the one of the most important factors and achievement of the indoor thermal comfort for building occupants represents a substantial objective, which should be satisfied in order to provide appropriate working and health conditions [14.

According to the study of Zhang et al. 15, some differences can be found in the terms of ideal indoor temperature. In China, the indoor comfort zone is around $21.7^{\circ} \mathrm{C}$, while the ideal indoor temperature in Europe is $23.4^{\circ} \mathrm{C}$. Therefore, many studies were proposed in order to optimize the indoor thermal comfort, natural ventilation, employment of the HVAC system. However, the maintenance of the ambient conditions directly affects the energy need for the heating or cooling purposes.

Importance of the maintenance of ambient air is connected not only with comfort of building occupants, but also with health issues. The negative health consequences of the undesirable indoor conditions, such as overheating and low or high relative humidity, consist in irritation of eyes, dryness of skin and throat, reduced work efficiency and respiratory problems [16]. Moreover, the higher risk of condensation may cause material defacement and proliferation of microorganisms [17. The risks of water vapour condensation, frost damage and mould growth should be considered in all renovation and building insulation works 18 .

Within this study, an outdated institutional building from 1960s is subjected to a long-term temperature and relative humidity monitoring beginning in 2012 . Based on the preliminary data, overheating during the summer period and substantial heat losses during the winter period resulted in a high energy consumption. The installation of the additional external insulation system was done in autumn/winter 2013, in order to improve the indoor environment quality for building inhabitants and decrease of sensitivity of the building to the exterior temperature fluctuations. The performance of the applied insulation systems is evaluated on the basis of the comparison of the long-term monitoring data before and after conducted reconstruction works.

\section{EXPERIMENTAL}

\subsection{Studied BUilding}

The investigations were done on the institutional building built in 1960s, located in the north-west suburb part of Prague, the capital of the Czech Republic. The studied building is composed of reinforced concrete column structure having 3 stories. The exterior envelope is constructed from the hung facade slabs formed of steel frames, aluminous window frames, glass, and insulation boards. Part of the envelope is built from cavity brick blocks provided on the surface by cement-lime plaster. 


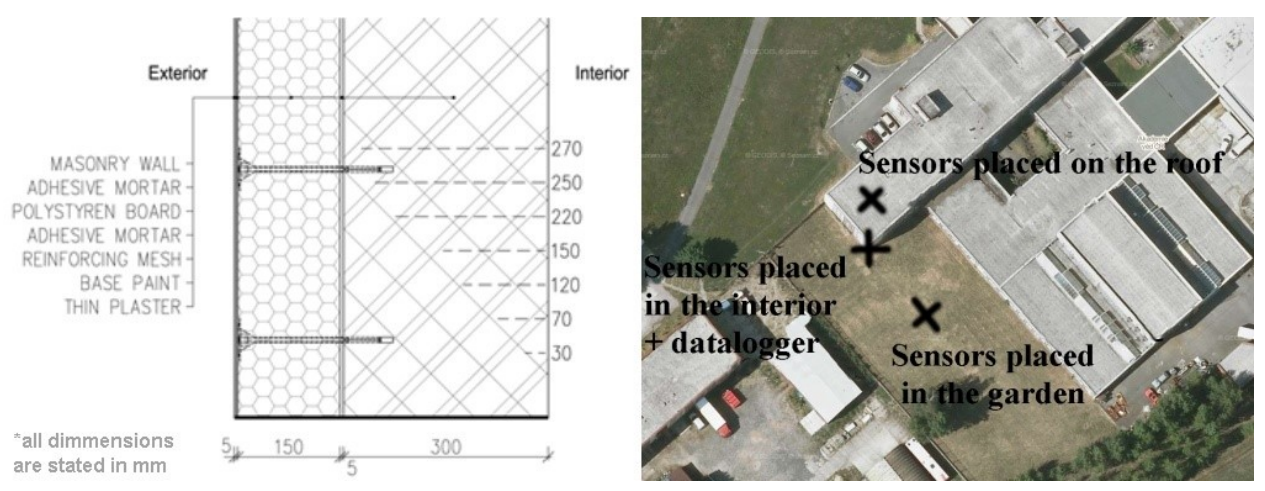

Figure 2. Scheme of sensors placement.

\begin{tabular}{lcc}
\hline Element & \multicolumn{2}{c}{$U$-value $\left[\mathrm{W} / \mathrm{m}^{2} \mathrm{~K}\right]$} \\
\cline { 2 - 3 } & Initial state & Final state \\
\hline Facade & 1.12 & 0.29 \\
Roof & 0.86 & 0.15 \\
Window & 2.40 & 1.21 \\
Door & 1.72 & 1.22 \\
\hline
\end{tabular}

TABle 1. Summarized description of initial and final state of studied building.

The additional exterior contact thermal insulation system was applied during autumn 2013 (October-December). It consists of adhesive mortar JUB JUBIZOL (polymer-modified micro-reinforced cement mortar mixture) used for gluing insulation boards and, as a brown coat, expanded polystyrene board EPS PERIMETR having a thickness of $150 \mathrm{~mm}$, alkali resistant reinforcing mesh, acrylic base paint UNIGRUND applied under thin-film plasters and water vapour permeable siloxane plaster UNISIL G with fungicidal additives. The insulation boards are fastened by fixing plastic/metal anchors. The outside view of the reconstructed building envelope and applied thermal insulation system is given in Figure 1

The monitoring of the hygrothermal performance was done for the part of the envelope formed by cavity brick blocks and exterior and interior plasters. This part of the building facade is considered to be the main cause of the heat losses of the building. Here, the material durability problems are also expected. New windows with insulating glazing and frames together with new insulated door and gates were placed in order to improve the thermal stability of the building. Summarized information of the initial state of the building is described in Table 1 .

\subsection{HVAC SYSTEM}

Studied building is not equipped with its own heat source, but is connected to the central heat supply system. The time heat regulation is installed only for the administrative part of the building and the rest is equipped only with thermostatic valves. There is no regulating fitting on the return pipes. Running of the heating system is ensured by suitable pumps with a continuous regulation.

However, due to the size of the object, it is possible to consider the heating system at the main points and meeting the requirements of the Decree No. 194/2007. However, the regulation of hydraulic regulation is not optimal. The thermal insulation of heat distribution pipes is in a good visual condition and energy losses related to the material conditions are approximately $7 \%$. The object is not equipped by any ventilation or $\mathrm{A} / \mathrm{C}$ devices; only portable $\mathrm{A} / \mathrm{C}$ devices are partly used. Ventilation is managed only naturally by opening windows.

\subsection{Sensors PlaCing}

The tested structure was continuously monitored by relative humidity and temperature measurements. Here, the combined mini-sensors, produced by Ahlborn (Germany), which allow a measurement of the relative humidity in the range of humidity of 5-98\% and the accuracy within $\pm 2 \%$, the resistance temperature sensors have the accuracy of $\pm 0.4^{\circ} \mathrm{C}$ in the temperature range of -20 to $0^{\circ} \mathrm{C}$ and $\pm 0.1^{\circ} \mathrm{C}$ in range of $0-70^{\circ} \mathrm{C}$ were used. The particular sensors were connected with the measuring unit that was controlled by a computer. The data were continuously collected, whereas the experiment was operated by a remote computer station. In total, 16 measuring channels were installed. The measurement runs from April 2012 and still continues. The sensor placement is shown in Figure 2, Dimensions used for the sensor placement description are stated in $\mathrm{mm}$.

Together with the monitoring of temperature and relative humidity profiles, the simultaneous measurement of the exterior climatic conditions was done by using the weather station Fiedler-Mágr (Czech Republic) with 16 recording channels. The following sensors were applied: W2t for the measurement of wind velocity and direction (heated version), RV12 for the relative humidity and temperature measurement, psychrometer SR02 with a collecting board of $200 \mathrm{~cm}^{2}$ and with a distinction of $0.2 \mathrm{~mm}$, and pyranometer for the measurement of global solar radiation. The weather station was placed on the roof of the studied building. 


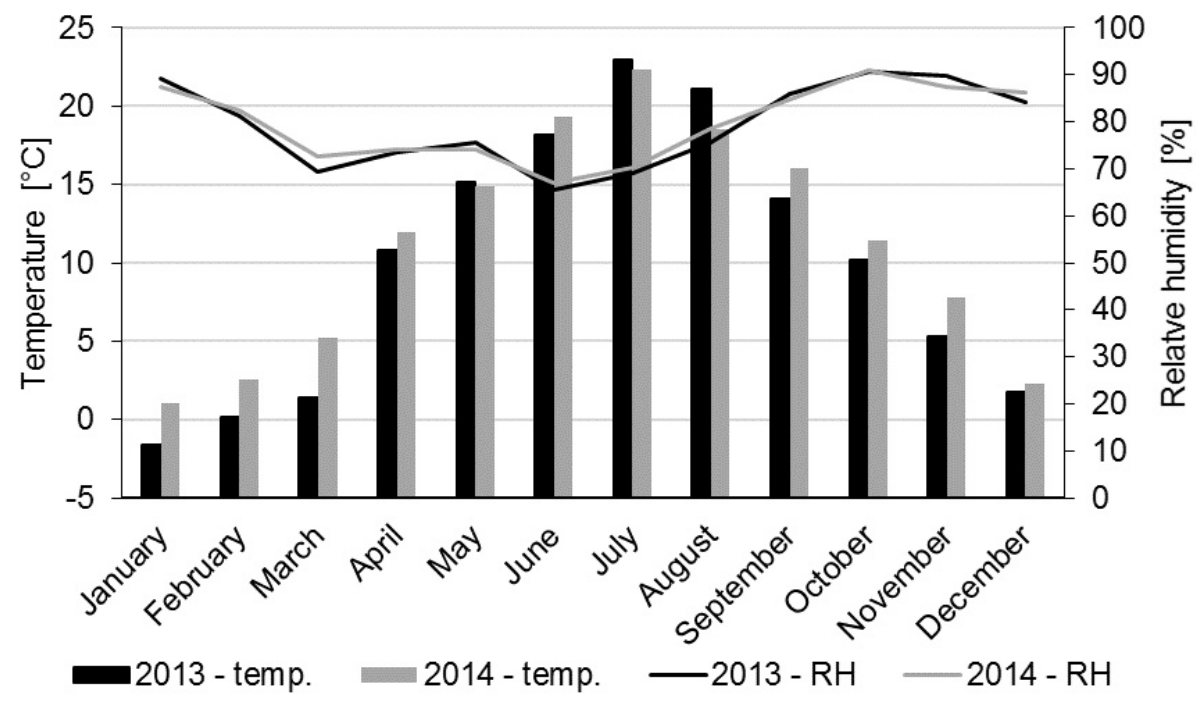

FiguRE 3. Average monthly climatic data.

\section{Results AND Discussion}

The exterior climatic conditions, namely the monthly average temperatures and the monthly average relative humidity, are shown in Figure 3 Here, an overview and a year-by-year comparison show only minor differences between the average values of monitored outdoor conditions. In general, the average monthly temperature was slightly higher in 2014 compared to 2013, which was more distinct during spring and autumn.

\subsection{Seasonal fluctuations}

\subsubsection{TEMPERATURE PROFILES}

The temperature profiles in selected representative days from spring, summer, autumn and winter are presented in Figure 4, where distinct differences can be observed. Temperature profiles were determined for selected days, which allows year-to-year comparison based on the similar day weather conditions. Days selected within the evaluation represent critical exterior conditions typical for the particular period, for example, high temperature during summer and low during winter period. This selection allows an assessment of the applied insulation layer by temperature profiles, which are typical for certain period and represent exterior climate loads. For the day used for description of 2012, the corresponding days with very similar temperature and relative humidity were identified and further analysed.

The conditions before application of the insulation system were unpleasant, especially for the building occupants, as an apparent thermal discomfort (during summer and autumn season) was noted. To be specific, temperature during summer reached almost $28^{\circ} \mathrm{C}$ and in autumn dropped to $20^{\circ} \mathrm{C}$. In terms of ideal indoor temperature [15], this unsatisfactory state requires a remediation. The undesirable indoor environment could certainly affect the work efficiency and health of building occupants in a negative way.
According to the temperature profiles from 2013 (before reconstruction) plotted in Figure 4 it is possible to conclude that the building envelope suffered from the changing climatic conditions and the thermal stability was considerably poor. However, temperature profiles from the summer period referred to building overheating problems and a necessity to apply additional cooling devices [19]. From the perspective of building occupants, the interior temperature of almost $28^{\circ} \mathrm{C}$ was very unpleasant and worsened the quality of the working environment [9]. It was revealed that the interior temperature remained high due to the heat solar gains through the hung façade system. In the light of these findings, the application of external insulation system was urgent in order to improve the thermal performance of the outdated building envelope [20]. The importance of the consideration of the day temperature peak was studied by [21. Here, continuous monitoring was used in order to estimate the time of the temperature peak of several buildings. Obtained results point to the substantial influence of the building orientation and consequent differences between energy released during various day periods or seasons. A complex assessment of a campus building in France, including different aspects, allowed to overcome the dilemma between the comfort and energy efficiency. An employment of a PVM (predicted mean vote) and a PPD (predicted percentage of dissatisfied) revealed, in some cases, situations, when certain phenomena induce thermal discomfort and an increased energy consumption at the same time [22]. Conducted research focused on the influence of seasonal variations on the indoor temperature clarified fluctuation. Authors concluded that neutral temperature is higher in autumn compared to spring, due to a higher number of used fans and opened windows. Thus, occupants feel cooler at the same temperature in autumn, as a result of higher indoor air velocity. 


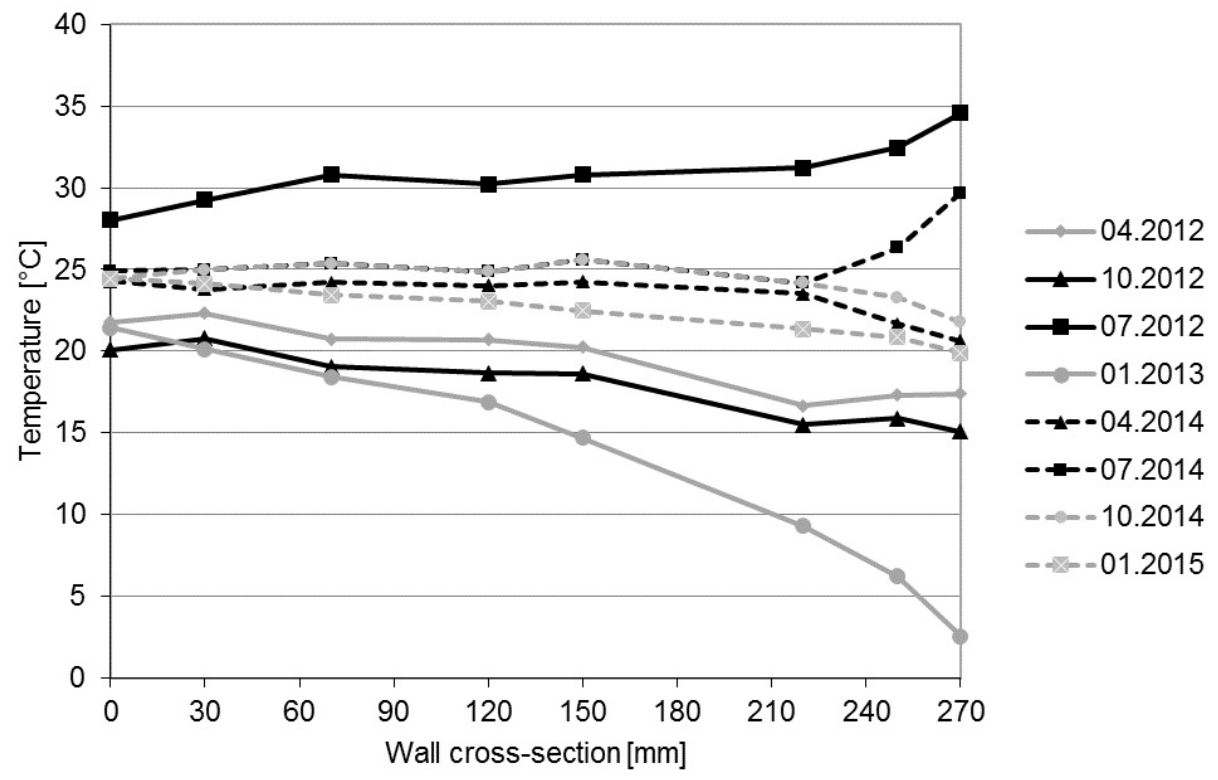

Figure 4. Seasonal comparison of temperature profiles.

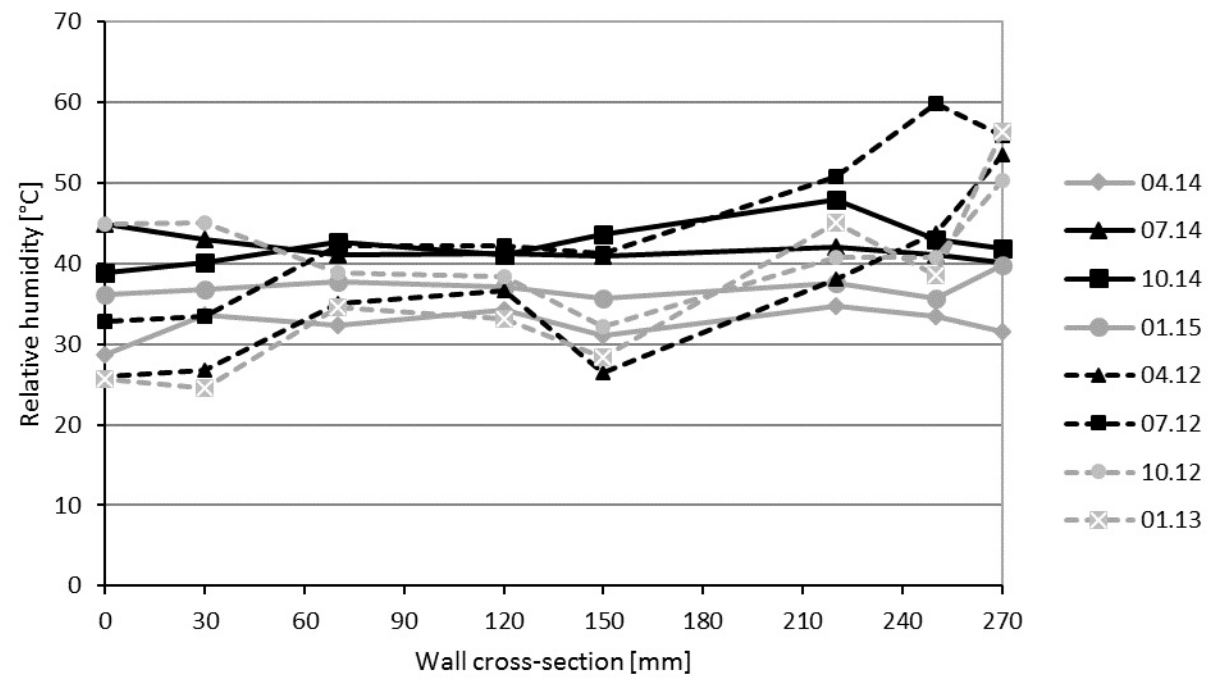

Figure 5. Seasonal comparison of relative humidity profiles.

The temperature profiles measured after the installation of the thermal insulation layer show a significant effect of the applied layer towards energy sustainability and better thermal stability. The insulation layer, formed by a mineral wool, substantially reduced the negative effect of temperature fluctuations on the interior temperature response. Compared to the temperature data before reconstruction, the temperature profiles in the load bearing structure exhibited a lower temperature gradient. This fact can be assigned to the significant improvement of the thermal performance of the building envelope. In general, the average indoor temperature, about $26.5^{\circ} \mathrm{C}$ during the summer period, was decreased to the more comfortable $23.2{ }^{\circ} \mathrm{C}$. Moreover, costs related to the building maintenance, particularly heating, were substantially reduced - approximately by half .

\subsubsection{RELATIVE HUMIDITY PROFILES}

The representative relative humidity profiles in the wall cross-section obtained during winter, spring, summer and autumn are given in Figure 5. The obtained values referred to a low level of the indoor relative humidity, which could have a negative influence on occupants' health (eye irritation, dry throat) and work efficiency, especially during winter period when the $\mathrm{RH}$ level drops below $30 \%$. However, for the rest of the year, relative humidity values are kept in the comfort zone and the ambient condition are satisfactory for building inhabitants. From this point of view, the application of the thermal insulation layer did not have any substantial effect on indoor relative humidity levels. Here, only minor changes were obtained within year-to-year comparison, for example, a slight decrease of the indoor air humidity was observed. The 


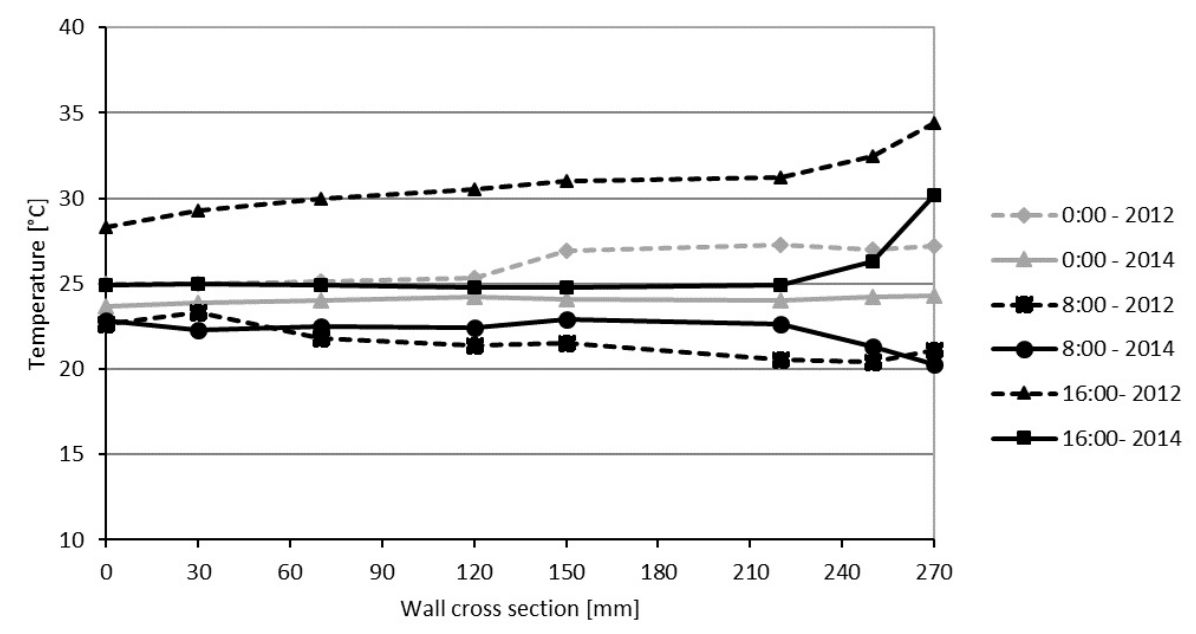

FiguRE 6. Daily comparison of temperature profiles.

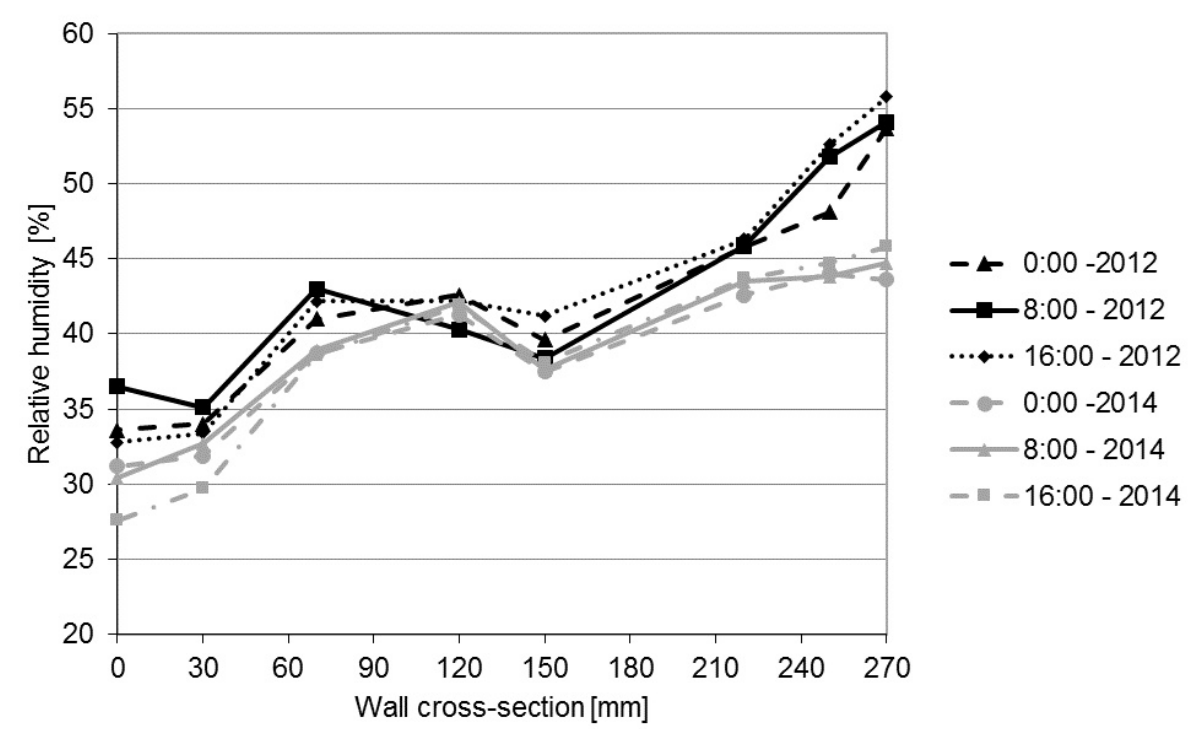

FiguRE 7. Daily comparison of relative humidity profiles.

effect of the application of thermal insulation layers on the indoor relative humidity was studied, e.g., by Korjenic et al. [23] with similar conclusions. This problem is widely analysed in modern low energy and passive houses, where the application of insulation polystyrene layer has a negative effect on the relative humidity level. Here, the air recuperation is the mostly used way to moderate the relative humidity level and keep it in the desired range in order to eliminate health risks related to the low level of relative humidity. The low level of relative humidity measured during 07.2014 can be attributed to the use of the portable $\mathrm{A} / \mathrm{C}$ device in order to reduce the increased indoor temperature.

\subsection{DAILY TEMPERATURE FLUCTUATIONS}

Diurnal changes in the exterior conditions, especially during certain periods such as sunny springs days, when nocturnal temperature often drops below the zero, represent considerable burden for the building envelope, especially due to the possible risk of water vapour condensation. Moreover, daily temperature variations in the cross section wall refer to the unstable and undesirable conditions. A low thermal performance of the building envelope is responsible for the higher energy consumption required for maintenance of the indoor thermal comfort. Furthermore, a low thermal inertia plays an important role during temperature peaks and significantly affects the quality of the interior climate for building occupants. The employment of additional cooling devices is unfortunately accompanied with higher energy demands 24. Also, it is not always possible to use these devices due to space limitations and, last but not least, the operational noise of portable cooling devices substantially limits their utilization on a daily basis. It should be noted, that the application of the central $\mathrm{A} / \mathrm{C}$ solution is not widespread in the Czech Republic in institutional buildings. 
In the measurements performed in this paper, the negative effect of the daily temperature fluctuations was successfully minimized by the application of the mineral wool thermal insulation layer. The overheating of the building was substantially reduced, as it is documented in Figure 6 . In the light of these findings, one can conclude that the indoor thermal comfort was significantly improved and occupants did not suffer from the high temperatures. In this case, days with high temperature values were submitted for evaluation of the influence of applied insulation system. For this purposes, days with temperature about $34.5^{\circ} \mathrm{C}(14: 00)$ were selected in order to access maximal temperature load induced by the exterior weather conditions, which significantly affect the ambient conditions. The reason for choosing the summer period is based on the problems related to a room overheating. During the winter period, almost no changes are observed because temperature profiles are strongly connected with the building heating, and the changes are compensated by the increased energy consumption.

The daily variation of the relative humidity level was negligible, as it is illustrated in Figure 7. In order to access diurnal relative humidity fluctuation, the typical winter days with $78.6 \% \mathrm{RH}$ were used for this comparison.

The application of the thermal insulation layer did not affect the relative humidity profiles in the wall cross-section, however, lower values of the relative humidity poses a possible health risk related to the building occupants as was stated above. Notwithstanding, the diurnal fluctuation are only minor and from this point of view, no significant changes occurred.

\section{Conclusions}

The evaluation of the functionality of the thermal insulation system applied on the outdated institutional building from 1960s proved its beneficial influence on the thermal stability. Thanks to the installed sensors in different depths, it was possible to perform a continuous monitoring of temperature and relative humidity fluctuations related to the changing exterior climatic conditions. A detailed analysis of the prereconstruction conditions in the building envelope allowed the identification of fundamental factors, which substantially influenced the obtained results and the previous low thermal performance. Together with the seasonal variations, the diurnal fluctuations of studied parameters were also identified as critical factors for the seasonal and daily overheating. The comparison of the temperature and relative humidity profiles in the wall cross-section between the pre-reconstruction state and after reconstruction confirmed substantial improvements achieved in the field of the thermal stability, resulting in more comfortable conditions for building occupants. The obtained results also showed decreased energy consumption demands.

\section{ACKNOWLEDGEMENTS}

This research has been supported by the Czech Science Foundation, under project No GBP105/12/G059.

\section{REFERENCES}

[1] IEA, CO2 Emissions from Fuel Combustion. International Energy Agency. Paris, France, p. 512, 2008.

[2] EU Commission, Commission Delegated Regulation (EU) No. 244/2012 supplementing Directive 2010/31/EU of the European Parliament and of the Council on the energy performance of buildings. Official Journal of the European Union, 2012.

[3] Berry, S., Whaley, D., Davidson, S., Saman, W.: Near zero energy homes - What do user think?, Energ.

Policy, 73, 2014, p. 127-137, DOI:doi.org/10.1016/j.enpol.2014.05.011

[4] Ascione, F., Bianco, N., Bottcher, O., Kaltenbrunner, R., Vanoli, G.P.: Net zero-energy buildings in Germany: Design, model calibration and lessons learned from a case-study in Berlin. Energy Build., 133, 2016, p. 688-710. DOI:10.1016/j.enbuild.2016.10.019

[5] Carbonara, G.: Energy efficiency as a protection tool, Energy Build. 95, 2015, p. 9-12, DOI:10.1016/j.enbuild.2014.12.052

[6] Balaras, C.A.: European residential buildings and empirical assessment of the Hellenic building stock, energy consumption, emissions and potential energy savings, Build. Environ., 42, 2007, p. 1298-1314, DOI:10.1016/j.buildenv.2005.11.001

[7] Batista, A. P., Freitas, M. A., Jota, F. G.: Evaluation and improvement of the energy performance of a building's equipment and subsystems through continuous monitoring. Energy Build., 75, 2014, p. 368-381, DOI:10.1016/j.enbuild.2014.02.029

[8] Guerra-Santin, O., Tweed, Ch. A.: In-use monitoring of buildings: An overview of data collection methods. Energy Build., 93, 2015, p. 189-207, DOI:10.1016/j.enbuild.2015.02.042

[9] Citherlet, S., Hand, J.: Assessing energy, lighting, room acoustic, occupant comfort and environmental impacts performance of building with a single simulation program. Build. Environ., 37, 2002, p. 845-856. DOI:10.1016/S0360-1323(02)00044-6

[10] Berry, S., Davidson, K.: Zero energy homes - Are they economically viable? Energ. Policy, 85, 2015, p. 12-21, DOI: $10.1016 /$ j.enpol.2015.05.009

[11] Chantrelle, F.P., Lahmidi, H., Keilholz, W., El Mankibi, M., Michel, P.: Development of a multicriteria tool for optimizing the renovation of buildings, Appl. Energy, 88, 2011, p. 1386-1394, DOI:10.1016/j.apenergy.2010.10.002

[12] Moatassem, A., El-Rayes, K., Liu, L.: Economic and GHG Emission Analysis of Implementing Sustainable Measures in Existing Public Buildings, J. Performance Constr. Facilit., Vol. 30, No. 6, 2016, p. 165-174. DOI:10.1061/(ASCE)CF.1943-5509.0000911

[13] Miulčioniene, R., Martinaitis, V., Keras, E.: Evaluation of energy efficinecy measures sustainability by decision tree method. Energy Build., 76, 2014, p. 64-71, DOI:10.1016/j.enbuild.2014.02.048. 
[14] Ascione, F., Bianco, N., De Masi, R. F., Vanoli, G. P.: Rehabilitation of the building envelopes of hospitals: achievable energy savings and microclimatic control on varying the HVAC systems in Mediterranean climates. Energy Build., 60, 2013, p. 125-138. DOI:10.1016/j.enbuild.2013.01.021

[15] Zhang, N., Cao, B., Wang, Z., Zhu, Y., lion, B.: A comparison of winter indoor thermal envinronment and thermla comfort between regions in Europe, North America and Asia, Build. Environ., 117, 2017, p. 208-217, DOI:doi.org/10.1016/j.buildenv.2017.03.006

[16] Zhang, H, Gong, N., Zhao, L.: Indirect effects of air-conditioning relative humidity of hospital buildings in summer on human health. Journal of Central South University (Science and Technology), 43, 2012, p. 3727-3733.

[17] Dall'O, G., Sarto, L., Galante, A., Pasetti, G.: Comparison between predicted and actual energy performance for winter heating in high-performance residential buildings in the Lombardy region (Italy). Energy Build., 47, 2012, p. 247-253. DOI:10.1016/j.enbuild.2011.11.046

[18] Toftum, J., Jorgensen, A. S., Fanger, P. O.: Upper limits for indoor air humidity to avoid uncomfortably humid skin. Energy Build., 28, 1998, p. 1-13. DOI:10.1016/S0378-7788(97)00017-0.

[19] Brunner, S., Simmler, H.: In-situ performance assessment of vacuum insulation panels in a flat roof construction. Vacuum, 82, 2008, p. 700-707, DOI:10.1016/j.vacuum.2007.10.016

[20] Kruger, E., Givoni, B.: Thermal monitoring and indoor temperature predictions in a passive solar building in an arid environment. Build. Environ., 43, 2008, p. 1792-1804. DOI:10.1016/j.buildenv.2007.10.019

[21] Sham, J. F. C., Memon, S. A., Lo, T. Y.: Application of continuous surface temperature monitoring technique for investigation of nocturnal sensible heat release characteristics by building fabrics in Hong Kong, Energy Build., 58, 2013, p. 1-10, DOI:10.1016/j.enbuild.2012.11.025

[22] Allab, Y., Pellegrino, M., Guo, X., Nefzaoui, E., Kindinis, A.: Energy and comfort assessment in education building: Case study in a French university campus, energy Build., 143, 2017, p. 202-219, DOI:10.1016/j.enbuild.2016.11.028

[23] Korjenic, A.; Teblick, H.; Bednar, T.: Increasing the thermal indoor humidity levels in buildings with ventilation systems: Simulation aided design in case of passive houses. Building Simul., 2010, p. 295-310, DOI:10.1007/s12273-010-0015-2

[24] Andersen, R., Fabi, V., Corgnati, S.: Predicted and actual indoor environmental quality: verification of occupants' behaviour models in residential buildings. Energy Build. 127, 2016, p. 110-115. DOI:10.1016/j.enbuild.2016.05.074 